\title{
Сбалансированная система показателей в качестве ин- струмента контроля Стратегии национальной безопасности
}

\author{
Анета Новаковска-Кристман *
}

\section{Введение}

Равновесие Нэша предполагает, что государства могут достичь состояния равновесия, если ни одно из них не выделяется среди других каким-либо образом. Это, наряду с фактом того, что некоторые страны сознательно делают другие страны более бедными в процессе их собственного развития - хотя и дают им компенсации, которые превышают перенесенные потери (критерий эффективности Калдора-Хикса), - все равно приводит к более динамичному развитию в странах, которые получают выгоду, чем в странах, которые несут потери. Это ведет к несоответствиям в динамике развития разных стран и является одним из объяснений существования социального недовольства. Однако, существование угроз, проистекающих из различий между странами в уровнях их развития, является только одним из многих факторов, которые влияют на проблемы безопасности как для отдельных стран, так и для регионов и мира в целом.

Все люди интуитивно понимают проблему безопасности; более того, большинство людей согласны, что это важная проблема. Безопасность является основной потребностью отдельных людей, социальных групп - а на деле, каждого субъекта, в том числе и наций. (Для целей этой статьи мы будем называть эти субъекты бенефициарами безопасности). Безопасность связана с надежностью существования, собственности, функционирования и развития. Проблема состоит в том, что безопасность не является состоянием, которого можно просто достичь раз и навсегда, она требует постоянных действий, чтобы обеспечивался приемлемый уровень безопасности. ${ }^{1}$ Безопасность зависит от множества факторов во внешней и внутренней среде. Анализ этих факторов требует постоянного контроля, и любые полученные выводы становятся основой для действий, которые в свою очередь должны быть объектом контроля. Контроль так же учитывает последствия предпринятых и выполненных действий. Надо отметить, что при обсуждении контроля необходимо учитывать разнообразные аспекты (фигура 1). Наиболее упрощенная дефиниция контроля предполагает, что это есть процесс сравнения требуемого и реального состояния.

Анета Новаковска-Кристман получила степень доктора философии в Варшавском Университете. В настоящее время она является адъюнкт-преподавателем Института менеджмента Национального Университета Обороны Польши. Интересуется вопросами менеджмента, и в частности, стратегическим анализом, включая проектирование и реализацию стратегий.

1 Adam D. Rotfeld, Europejski system bezpieczeństwa in statu nascendi (Warsaw: PISM Publishing House, 1990), 5. 
Существует тесная связь между контролем и планированием, поскольку контроль позволяет измерить прогресс к достижению конкретных целей и дает возможность вариантного адаптирования начального плана. В этом эссе я попыталась объяснить проблему контролирования полученных результатов. Здесь было использовано упрощенное определение контроля, однако, в расширенном варианте, который проистекает из применяемой методологии, основанной на концепции Сбалансированной системы показателей (ССП). Такой подход обусловлен попыткой представить возможности применения ССП при контроле реализации стратегии в органах государственной администрации, следуя примеру стратегии национальной безопасности. Таким образом, тезис основывается на наиболее популярном инструменте, используемом при планировании, осуществлении и контроле стратегии: сбалансированной системы показателей. Он исследует процесс стратегического менеджмента с позиции причина-следствие, и рассматривает корреляцию между выбранной стратегией и определенными действиями, и индикациями, которые предназначены для контроля их результатов путем использования тщательно выбранных количественных и качественных показателей. Однако, оценочные индикаторы не обязывают сотрудников и организационных структур строго следовать предварительно согласованному плану. Таким образом система индикаторов понимается как система коммуникации, обмена информацией и обучения, а не как система контроля. ${ }^{2}$ В этой работе, однако, данный инструмент используется для того, чтобы показать наличные возможности контроля, которые будут способствовать достижению стратегических целей стратегии национальной безопасности.

\section{Стратегический надзор}

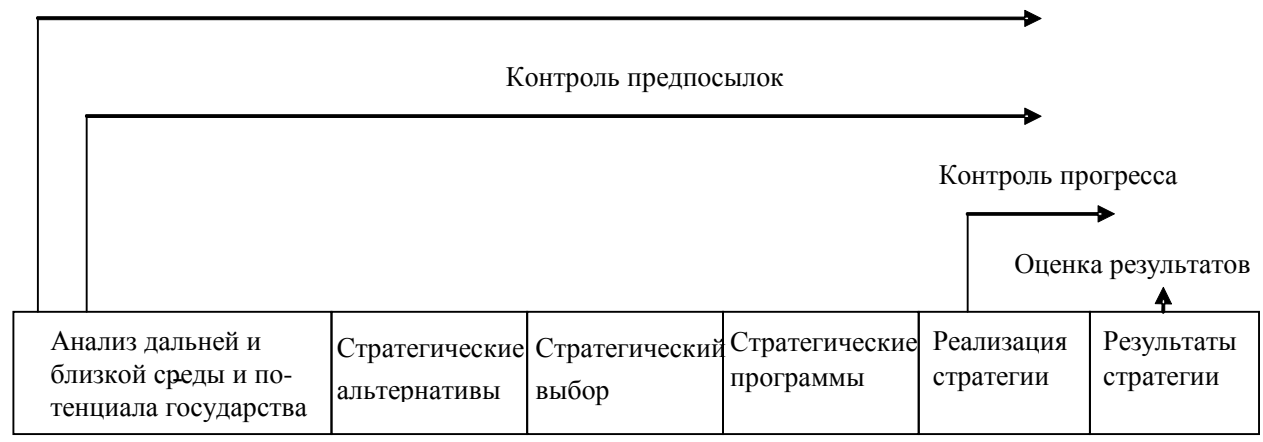

Фигура 1: Виды стратегического контроля. ${ }^{3}$

2 Robert S. Kaplan and David P. Norton, Strategiczna karta wyników, Jak przełożyć strategię na działanie (Warsaw: PWN, 2001), 42.

3 Согласно T. Gołębiowski, Zarzadzanie strategiczne. Planowanie i kontrola (Warsaw: Difin, 2001). 


\section{Стратегия национальной безопасности}

Стратегия не может быть ограничена до общего мировоззрения исполнительной власти. В классическом понимании, стратегия трактуется как метод, с помощью которого реализуются стратегические цели. ${ }^{4}$ Сказав это, стоит подчеркнуть, что стратегические цели, в случае стратегии национальной безопасности, прежде всего должны быть сфокусированы на нуждах бенефициаров в сфере безопасности.

Определение безопасности, и как естественное следствие этого стратегические цели, зависит в большой степени от личного мнения: более того, определения, которые можно найти в литературных источниках, не являются взаимно исключающимися. При традиционном реалистическом подходе к вопросу безопасности вооруженные силы являются доминирующим фактором. Это означает, что обеспечение военной безопасности является приоритетом для государства, что подразумевает необходимость увеличивать могущество государства (в частности, военное могущество). Либеральная парадигма доказывает, что безопасность относится не только к государствам, но и к внутренним акторам (отдельным людям, социальным группам). В процессе анализа безопасности надо учитывать следующие аспекты: политический, экономический, социальный, культурный, идеологический и экологический. Неомарксистские теории ставят особое ударение на экономические проблемы, уделяя особое внимание имущим классам, поскольку государство реализует главным образом их цели. С этой точки зрения ключевыми субъектами безопасности являются не государства, а отдельные люди, которые располагают определенной собственностью. Конструкционизм, с другой стороны, определяет безопасность через разные аспекты идей и ценностей. ${ }^{5}$

Следовательно, национальная безопасность рассматривает как защиту интересов страны в целом, так и защиту интересов общества и его составляющих элементов, в том числе и отдельных людей. Таким образом, безопасность охватывает: ${ }^{6}$

- Устранение как внешних опасностей, так и внутренних слабостей (негативные деятельности)

- Обеспечение выживания, территориальной целостности, функционирования и свободного развития страны и ее народа (позитивные деятельности).

4 Смотри Z. Drążek and B. Niemczynowicz, Zarzadzanie strategiczne przedsiębiorstwem (Warsaw: PWE, 2003), 27; M. Rajzer, Strategie dywersyfikacji przedsiębiorstw (Warsaw: PWE, 2001), 13; S. Tilles, "How to Evaluate Corporate Strategy," Harvard Business Review 41 (July-August 1963): 111-121; M. Marchesnay, Zarządzanie strategiczne. Geneza i rozwój (Warsaw: Politext, 1994), 17.

5 J. Zając, "Bezpieczeństwo - aspekty terminologiczne," in Wspótczesny wymiar bezpieczeństwa. Między teoria a praktyka, ed. J. Pawłowski (Warsaw: RWO, 2011), 18.

6 Там же, 19. 
Вышесказанное приводит нас к определению безопасности как баланса между внутренними и внешними, текущими и потенциальными опасностями, и существованием противодействия, достаточно эффективного для того, чтобы обеспечить развитие страны и ее народа. Это означает, что внутренний потенциал и внутренние виды деятельности, позволяющие стране использовать внешние ресурсы, должны быть скоординированы с тем, чтобы служить национальным интересам, учитывая факт, что последний фактор определяется национальными и международными детерминантами.

Чтобы обеспечить безопасность разных бенефициаров, необходимо разработать методологию поведения. Рассматривая безопасность как процесс, ее можно представить в виде, показанном на фиг. 2. Здесь основной фокус лежит на реализации безопасности, осуществляемой на основе правил, которые разрабатываются методами стратегического менеджмента.

Правила для обеспечения условий безопасности должны найти отражение в стратегии, в нашем случае в стратегии национальной безопасности. Этот документ можно определить, как сочетание науки и искусства разработки с использованием и координированием национальных ресурсов для того, чтобы добиться целей, которые способствуют обеспечению национальной безопасности. ${ }^{7}$ Таким образом, реализация стратегии является процессом поиска ресурсов, которые при правильном использовании позволяют государству достичь своих стратегических целей. Поэтому, она должна быть сфокусирована на: ${ }^{8}$

- $\quad$ Развитии и адаптации организационных структур выбранной стратегии

- Введении и поддержке необходимых функций в выполняемых мероприятиях для того, чтобы принятая стратегия эффективно реализовалась

- Мониторинг конкретных фаз реализации стратегии

- Оценке результатов.

Контроль реализации, так же как и оценка результатов должны приводить к выводам и введению в действие мероприятий для устранения недостатков (фиг. 2).

Создание и развитие стратегии может быть основано на методологии сбалансированной системы показателей. В таком случае, процесс стратегического ме-

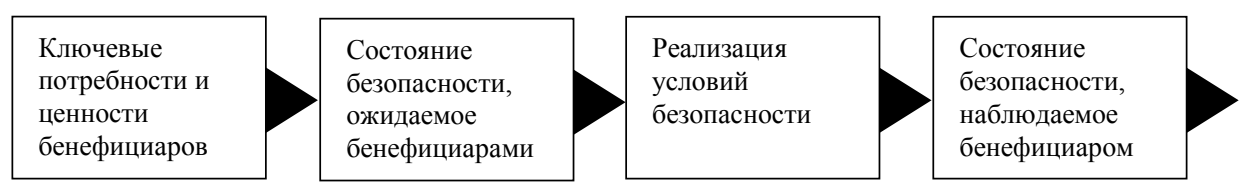

Фигура 2: Процессный подход к безопасности.

7 Сравни с Dictionary of Military and Associated Terms, Joint Publication 1-02 (Washington, D.C.: U.S. Department of Defense, 2001), 358.

8 E. Urbanowska-Sojkin, P. Banaszyk, and H. Witczak, Zarzadzanie strategiczne przedsiębiorstwem (Warsaw: PWE, 2007), 11. 
неджмента национальной безопасности может быть изображен как показано на фиг. 3.

Проектирование стратегии начинается с формулировки видения и уточнения миссии. Когда видение и миссия выкристаллизовались, можно начинать разрабатывать стратегические цели, отвечающие национальным интересам. ${ }^{9}$ Цели можно представить в виде «Дерева целей». Стратегические цели реализуются через стратегические задачи. Они могут быть приписаны определенным должностям, органам или людям. И не на последнем месте, необходимо предпринять меры, которые позволят людям, определяющим политику, оказывать влияние на реализацию целей (смотри фиг.4). Жизненно важными для реализации миссии, национальных

9 В литературе трудно найти четкую формулировку понятия национальный интерес. Сторонники политического реализма дефинируют его как синоним понятий выживание, безопасность, могущество и их производных. Авторы одного исследования Бруклинского института определяют национальный интерес как «систему общих и устойчивых целей, которые являются объектом деятельности государства». Из упомянутых целей вытекают прямые цели, которые затем превращаются в задачи для выполнения. Другие формулируют национальный интерес в перспективе, определяя его как цели, которые нация заявляет, что будет реализовывать в международных отношениях. В описательном смысле, национальный интерес связан с целями, которые реализуются в данный период времени. Лерс и Сейд рассматривают национальный интерес с точки зрения конечной цели, долгосрочных целей, среднесрочных целей, непосредственных целей и политических действий. Бровер предлагает заменить понятие «национальный интерес» такими понятиями как: общие цели, конкретные цели или стратегии. Шлейхер идет даже дальше, отказываясь от термина национальный интерес в пользу таких понятий как «основные цели» и «проистекающие непосредственные цели». Представитель неореалистической теории, Г. Модельски, предлагает отказаться от представления о национальном интересе, который подразумевает общество одного вида, и заменить его понятием «государственный интерес». Государственные интересы - это «требования, желания и стремления, касающиеся поведения других стран, они формулируются, чтобы затем политики их осуществляли». Таким образом, интересы формулируют цели, а цели формируют интересы. Следовательно, они скоррелированы. Другой неореалист, Дж. Френкел, остается верным концепции национальных интересов и различает три их уровня: уровень чаяний, оперативный уровень и полемический уровень. Смотри R. Zięba, "Bezpieczeństwo jako cel polityki państwa: aspekty teoretyczne," Współczesny wymiar bezpieczeństwa. Między teoria a praktyka, ed. J. Pawłowski (Warsaw: RWO, 2011), 22-24; и G. Modelski, A Theory of Foreign Policy (London: Praeger, 1962), 70-72.

Разделение интересов отличается в разных странах. В Польше они рассматриваются как жизненные, важные, существенные и т.д. Национальные интересы можно изучать в двух измерениях: абсолютном и относительном. Абсолютные национальные интересы связаны с безопасностью жизни граждан, выживанием нации и страны. Относительные национальные интересы проистекают из качества жизни людей и функционирования страны. Они адаптируются для реализации путем формулирования целей, которые становятся стимулом для предпринятия действий страной, в том числе действий на обеспечение условий безопасности. Смотри R. Zięba, "Bezpieczeństwo jako cel polityki państwa." 
интересов и целей являются: способы выполнения миссии; способы достижения целей и предпочтения при выборе ресурсов.

В конечном счете, анализ текущего положения безопасности фокусируется на разных субъектах, отдельных людях, социальных группах, институциях, организациях, системах и странах. Позиции, ожидания того, чему должна удовлетворять страна, менялись с течением времени. Поэтому анализ должен рассматривать разные аспекты безопасности, в том числе политическую, экономическую, культурную и военную безопасность - т.е. он должен рассматривать безопасность с точки зрения возможных рисков.

Установление стратегии национальной безопасности является процессом. ОН предполагает последовательность действий, выполняемых государством для того, чтобы обеспечить национальную безопасность на длительный период времени, учитывая разные ее аспекты. Это означает, что государство пытается поддерживать и развивать национальное могущество, ${ }^{10}$ чтобы быть в состоянии противодействовать всем опасностям в определенном окружении, располагая определенными местными ресурсами, а так же необходимой внешней поддержкой. ${ }^{11}$

Принятие методологии сбалансированных оценочных индикаторов может быть полезным при изготовлении формулы создания стратегии, полагая, что стратегия - это процесс, дающий возможность двигаться от видения к конкретным задачам, которые проистекают от установления измеримых целей. Любой сектор, который предоставляет услуги обществу, как ожидается, должен доводить до сведения общественности видение, миссию, цели и показатели, которые позволят государству оценивать результаты его работы. Предоставление таких услуг является необходимым условием для существования государства. Стоит дополнить, что ССП используется не только для объяснения и пропагандирования стратегии, - она является инструментом стратегического менеджмента. Следовательно, она направлена на развитие системы стратегического менеджмента. ${ }^{12}$

\section{Измерение стратегических целей национальной безопасности}

Жизненно важно определить стратегические цели национальной безопасности и измерители, которые к ним относятся. В нашем случае, стратегические цели воспринимаются как будущее желаемое состояние или результат активности страны в отдельно взятой стратегической сфере национальной безопасности.

В Стратегии национальной безопасности Республики Польша выделены восемь стратегических областей (смотри табл. 2, столб 1). Общие стратегические цели, связанные с национальной безопасностью, расписаны в Конституции Республики Польша от 1997 года ${ }^{13}$ и более подробно изложены в текущей стратегии

10 H. J. Morgentau, in Decyzje polityczne. Elementy teorii (Warsaw: A. Bodnar, 1985), 220.

11 See Alfred D. Chandler, Strategy and Structure in History of the American Enterprise (Cambridge, MA: Harvard University Press, 1992), 14.

12 Kaplan and Norton, Strategiczna karta wyników, 19, 171.

13 Bezpieczeństwo Narodowe Polski w XXI wieku (Warsaw: Bellona, 2006), 160, 171. 
национальной безопасности. ${ }^{14}$ Далее стратегические цели должны быть трансформированы в оперативные цели с помощью методологии менеджмента на основе целей путем использования ССП.

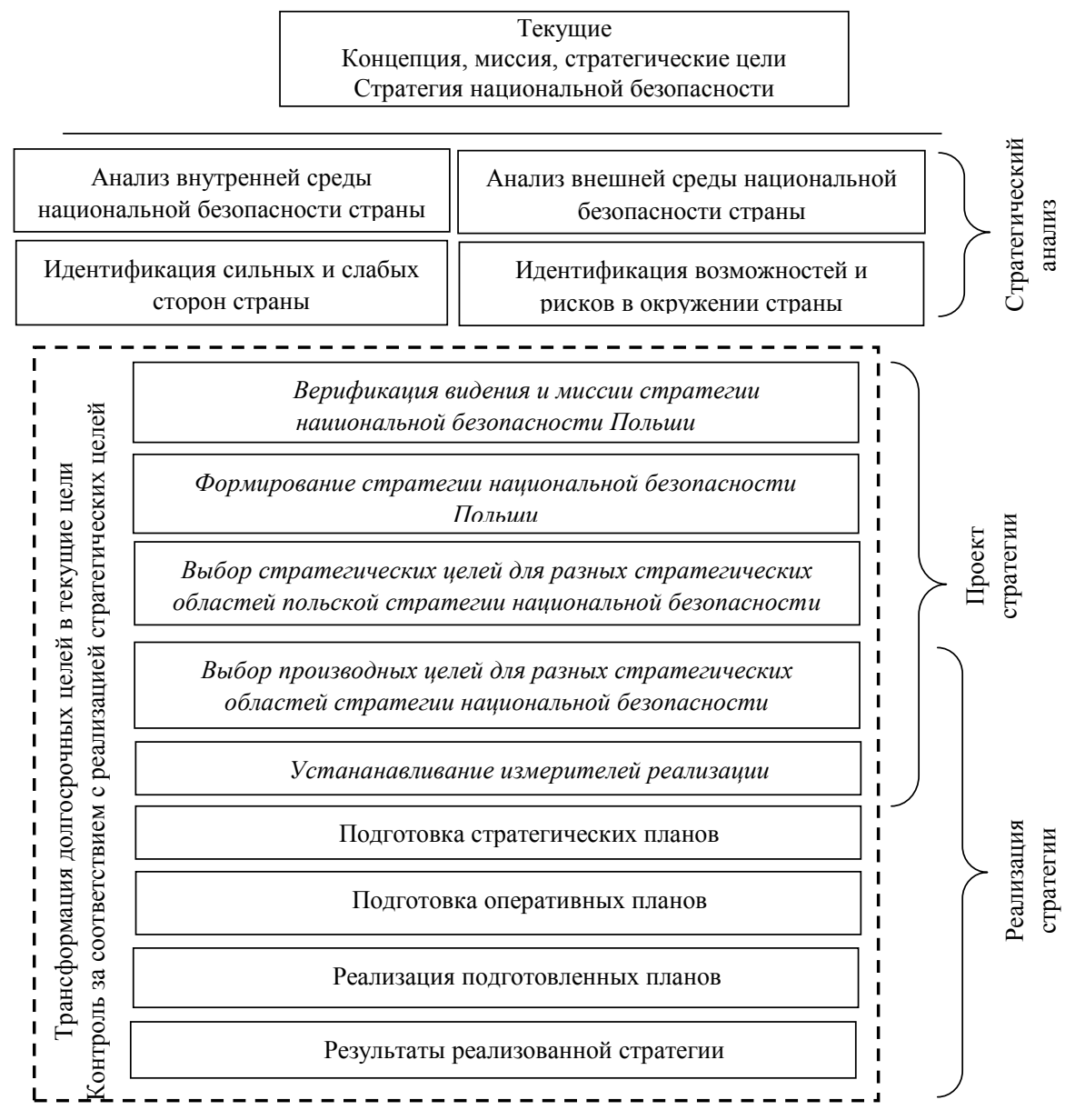

Фигура 3: Процесс стратегического менеджмента национальной безопасности на основе концепции ССП. ${ }^{15}$

14 Strategia bezpieczeństwa narodowego Rzeczpospolitej Polskiej (Warsaw, 2007), 5-6.

15 На основании D. A. Decenzo, Podstawy zarządzania (Warsaw: PWE, 2002), 146; K. Obłój, Strategia sukcesu firmy (Warsaw: PWE, 2000), 34; E. Urbanowska-Sojkin, P. Banaszyk, and 


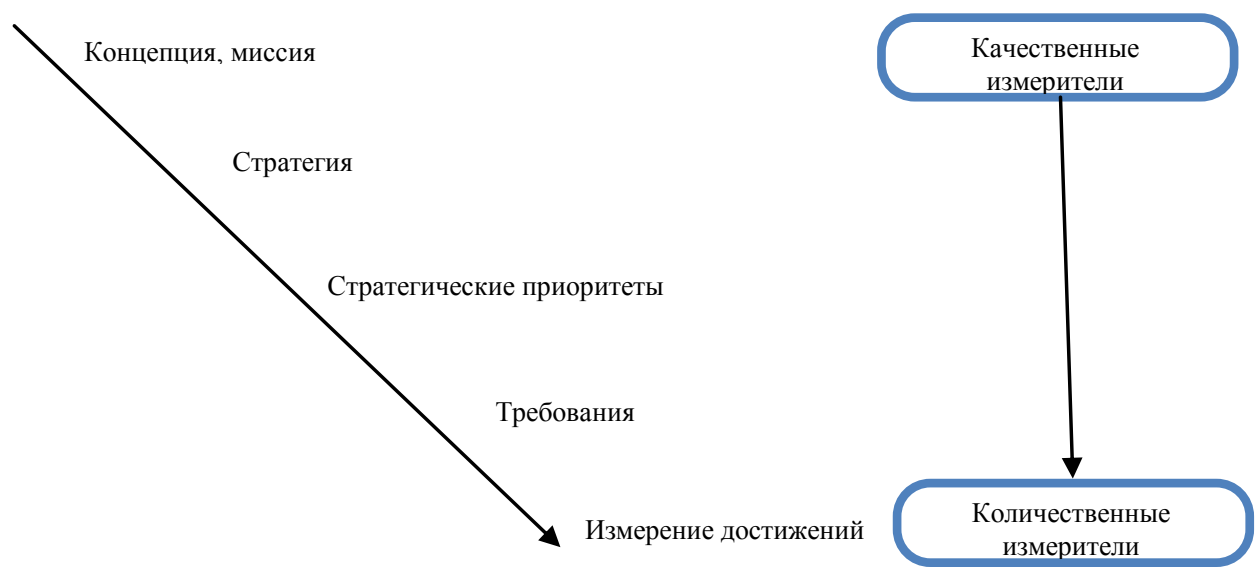

Фигура 4: Стратегия в измерителях. ${ }^{16}$

Стратегические сбалансированные показатели являются технологией менеджмента, которая, как показывают важные исследования, эффективна как в частном бизнесе, так и для институций, предоставляющих общественные услуги. После своего появления в 1980-х в качестве теории менеджмента эта система стала наиболее широко используемым методом в мире. ${ }^{17}$ Роберт Каплан и Дэвид Нортон разработали сбалансированные индикаторы для нужд организации эффективного мониторинга результатов реализации стратегии. Это было попыткой найти решение проблемы субъективных ошибок при применении и реализации принятых стратегий. Целью ССП было перевести высокие и довольно общие формулировки, используемые в организационной концепции и в декларациях миссии, на язык, понятный младшим менеджерам, путем использования системы каскадных задач. Таким образом, стратегия превращалась в оперативные цели, задачи, действия и деятельности с применением системы измерителей так, чтобы каждый мог бы сознательно способствовать успеху (смотри фиг. 5).

Измерители следует правильно выбирать и настраивать - только тогда они могут обеспечить информацию о текущей ситуации в данной организации и позволят менеджерам принимать соответствующие решения. Поэтому была создана многомерная система оценочных индикаторов, основанная на измерителях с четырех точек зрения (смотри табл. 1):

H. Witczak, Zarzadzanie strategiczne przedsiębiorstwem (Warsaw: PWE, 2007), 242; и Т. Gołębiowski, Zarzadzanie strategiczne. Planowanie i kontrola (Warsaw: Difin, 2001).

16 Согласно J. Czuchnowski, Balanced Scorecard (Gdańsk, 2002); доступно на www.zie.pg.gda.pl/zzti/dydaktyka/strategie_informatyzacji/si_bsc_wyklad.pdf.

17 Смотри Strategiczna Karta Wyników, доступно на www.bmconsult.pl/karta-wynikow-rsc.html; и Wdrażanie Strategicznej Karty Wyników; доступно на http://karstans.pl/wdrazaniestrategicznej-karty-wynikow, 67,11.html. 


\begin{tabular}{|c|c|c|c|c|c|}
\hline & $\begin{array}{l}\text { Стратегические } \\
\text { цели }\end{array}$ & $\begin{array}{c}\text { Единицы } \\
\text { измерения }\end{array}$ & $\begin{array}{l}\text { Программа } \\
\text { действий }\end{array}$ & $\begin{array}{l}\text { Выполняемые } \\
\text { деятельности }\end{array}$ & $\begin{array}{c}\text { Степень } \\
\text { реализации } \\
\text { цели } \\
\end{array}$ \\
\hline $\begin{array}{l}\text { С финансовой } \\
\text { точка зрения }\end{array}$ & \multicolumn{3}{|c|}{$\begin{array}{c}\text { Если что-то нельзя измерить, } \\
\text { то им нельзя и управлять }\end{array}$} & & \\
\hline $\begin{array}{l}\text { С точки зре- } \\
\text { ния бенефи- } \\
\text { циаров }\end{array}$ & & \multicolumn{3}{|c|}{$\begin{array}{c}\text { То, что может быть измерено, } \\
\text { может быть сделано }\end{array}$} & \\
\hline $\begin{array}{l}\text { С точки зре- } \\
\text { ния процесса }\end{array}$ & & \multicolumn{3}{|c|}{$\begin{array}{c}\text { Деятельность можно } \\
\text { вычислять }\end{array}$} & \\
\hline $\begin{array}{l}\text { С точки зре- } \\
\text { ния потенци- } \\
\text { ала }\end{array}$ & & & \multicolumn{3}{|c|}{$\begin{array}{c}\text { Вы не можете контролировать } \\
\text { неизмеримые цели }\end{array}$} \\
\hline
\end{tabular}

Фигура 5: Идея измеряемых целей в сбалансированной системе показателей. ${ }^{18}$

1. Финансовой

2. Потребительской (в нашем случае используется термин «бенефициар»)

3. Внутренних процессов

4. Потенциала (также называемой перспективой развития, увеличения, усовершенствования, знаний, инноваций).

Авторы рассматривают эту таблицу в качестве исходного варианта, который можно дополнять в зависимости от вида организации. (К примеру, институции, предоставляющие общественные услуги, часто анализируют свои организации с такой точки зрения, как они воспринимаются общественностью). Они предлагают определенную последовательность анализа. Следует начинать с точки зрения бенефициаров, поскольку это их потребности надо защищать. Способность обеспечивать потребности проистекает из процессов; следовательно, вторая анализируемая точка зрения - это внутренние процессы. Обе точки зрения характеризуются потенциальными параметрами. Они являются ключевыми элементами для эффективного удовлетворения потребностей бенефициаров в будущем. Финансовые измерители показывают, как стратегия субъекта способствует его развитию. Надо отметить, что финансовая точка зрения в случае рассматриваемого субъекта -

${ }^{18}$ Согласно Czuchnowski, Balanced Scorecard. 
страны - является не целью, а ограничением, поскольку расходы должны быть ограничены в рамках, предусмотренных бюджетом. ${ }^{19}$

Таблица 1: Отношение между временем и точками зрения $\mathrm{CCП}^{20}$

\begin{tabular}{|c|c|c|c|}
\hline $\begin{array}{l}\text { Точка } \\
\text { зрения }\end{array}$ & Характеристики & Цели & $\begin{array}{l}\text { Изме- } \\
\text { рители }\end{array}$ \\
\hline $\begin{array}{l}1 . \\
\text { Финансовая }\end{array}$ & $\begin{array}{l}\text { Представлены через финансовые показа- } \\
\text { тели, которые позволяют оценку финансо- } \\
\text { вых результатов применения стратегии. } \\
\text { Определяют, как реализуемая стратегия } \\
\text { влияет на экономическое состояние субъ- } \\
\text { екта, включая (среди прочих индикаторов) } \\
\text { прибыльность, расширение предоставляе- } \\
\text { мых услуг, расходы на персонал по отно- } \\
\text { шению к его эффективности. }\end{array}$ & $\begin{array}{l}\text { g1 } \\
\text { g2 } \\
\text { g3 }\end{array}$ & $\begin{array}{c}\mathrm{m} 1 \\
\ldots \\
\mathrm{m} 7\end{array}$ \\
\hline $\begin{array}{l}2 . \\
\text { Бенефици- } \\
\text { аров }\end{array}$ & $\begin{array}{l}\text { Целью является рыночный сегмент, в ко- } \\
\text { тором субъект намеревается предостав- } \\
\text { лять услуги. Мы используем измерители, } \\
\text { которые отражают роль субъекта в обслу- } \\
\text { живании бенефициаров. (отдельных лю- } \\
\text { дей, социальных групп, общество) Уро- } \\
\text { вень их удовлетворенности определяется } \\
\text { временем поставки, качеством, ценой и } \\
\text { функциональной стоимостью. }\end{array}$ & $\begin{array}{l}\text { g1 } \\
\text { g2 } \\
\text { g3 }\end{array}$ & $\begin{array}{c}\mathrm{m} 1 \\
\ldots \\
\mathrm{m} 7\end{array}$ \\
\hline $\begin{array}{l}3 . \\
\text { Внутренних } \\
\text { процессов }\end{array}$ & $\begin{array}{l}\text { Они представлены индикаторами, относя- } \\
\text { щимся к внутренним процессам, которые } \\
\text { имеют ценность для бенефициаров, к при- } \\
\text { меру, внутренняя коммуникация, техноло- } \\
\text { гия, эффективность сотрудников. }\end{array}$ & $\begin{array}{l}\text { g1 } \\
\text { g2 } \\
\text { g3 }\end{array}$ & $\begin{array}{l}\mathrm{m} 1 \\
\ldots \\
\mathrm{m} 7\end{array}$ \\
\hline $\begin{array}{l}4 . \\
\text { Потенциала }\end{array}$ & $\begin{array}{l}\text { Это измерители, которые являются осно- } \\
\text { вой долгосрочного развития и усовершен- } \\
\text { ствования, к примеру, усовершенствова- } \\
\text { ния продуктов или услуг, методов функ- } \\
\text { ционирования, расширенные функцио- } \\
\text { нальные качества. }\end{array}$ & $\begin{array}{l}\text { g1 } \\
\text { g2 } \\
\text { g3 }\end{array}$ & $\begin{array}{c}\mathrm{m} 1 \\
\ldots \\
\mathrm{m} 7\end{array}$ \\
\hline
\end{tabular}

19 A. Nowakowska-Krystman, "Strategiczna karta wyników jako narzędzie strategii bezpieczeństwa narodowego," in Strategia bezpieczeństwa narodowego. Część II - praca naukowobadawcza, ed. J. Gryz (Warsaw: NDU, 2011), 122.

20 Там же. 
В каждом из направлений есть набор измеримых, сбалансированных долгосрочных и краткосрочных целей, выбранных путем рассмотрения как финансовых, так и нефинансовых измерителей, которые служат показателями результатов оперативных деятельностей, а также внутренней и внешней эффективности. ${ }^{21}$ Учет диапазона перечисленных точек зрения предотвращает зацикливание на одном единственном измерителе, так как все они были выбраны из большой группы измерителей, и каждый из них одинаково важен для того, чтобы менеджмент мог оказывать влияние на практическую реализацию стратегии. При выборе измерителей оказывается полезно следовать принципу Парето (который гласит, что 80 процентов последствий проистекает только из 20 процентов причин). Кроме того, важно, чтобы критерии соответствовали правилу SMART (конкретные, измеримые, амбициозные, реалистические, привязанные к времени). Дополнительно они должны отличаться такими характеристиками как:

- Прямота, что означает прямую связь со степенью реализации цели

- Объективность, или недвусмысленная иллюстрация степени реализации цели

- Точность, что означает, что в случаях, когда трудно найти синтетический измеритель, отражающий степень реализации цели, рекомендуется создавать набор разных измерителей.

Сбалансированные показатели можно разделить на две группы: прослеживающие индикаторы, которые относятся к тому, что уже произошло; и направляющие индикаторы, которые прогнозируют будущее. Направляющие индикаторы часто имеют более качественный, чем количественный характер, давая информацию о том, как то, что уже произошло, может оказать влияние на функционирование субъекта в будущем. Важно отметить, что когда одной цели приписано больше одного показателя, необходимо определить, существует ли между ними отношение:

- Нейтральности: улучшение одного показателя не оказывает влияние на другие индикаторы

- Дополнительности: улучшение одного индикатора имеет положительное влияние на другие индикаторы

- Состязательности: улучшение одного показателя имеет отрицательное влияние на другие показатели.

Когда мы определяем, какими будут самые полезные показатели для целей, которые были установлены в восьми упомянутых областях безопасности Республики Польша (РП) - области стратегии безопасности соответствуют областям, перечисленным в Стратегии национальной безопасности Польши от 2007 года, - мы должны учитывать принятые точки зрения (смотри фиг.7). Эти точки зрения отличаются от указанных в табл.1, и определены в другой последовательности, кото-

21 Kaplan and Norton, Strategiczna karta wyników,166-67. 
рая проистекает из характера рассматриваемой проблемы. Модифицированная структура Сбалансированной системы показателей включает следующие точки зрения: $^{22}$

1. Бенефициаров: этот разрез в основном касается стремления удовлетворить ожидания стороны, обеспечивающей финансовые активы; ожидания сторон, получающих услуги; и ожидания налогоплательщиков, чтобы обеспечить их поддержку

2. Социальные выгоды: это включает выгоды для отдельных людей, социальных групп и организаций, которые проистекают из деятельности органов, обеспечивающих безопасность в определенных областях

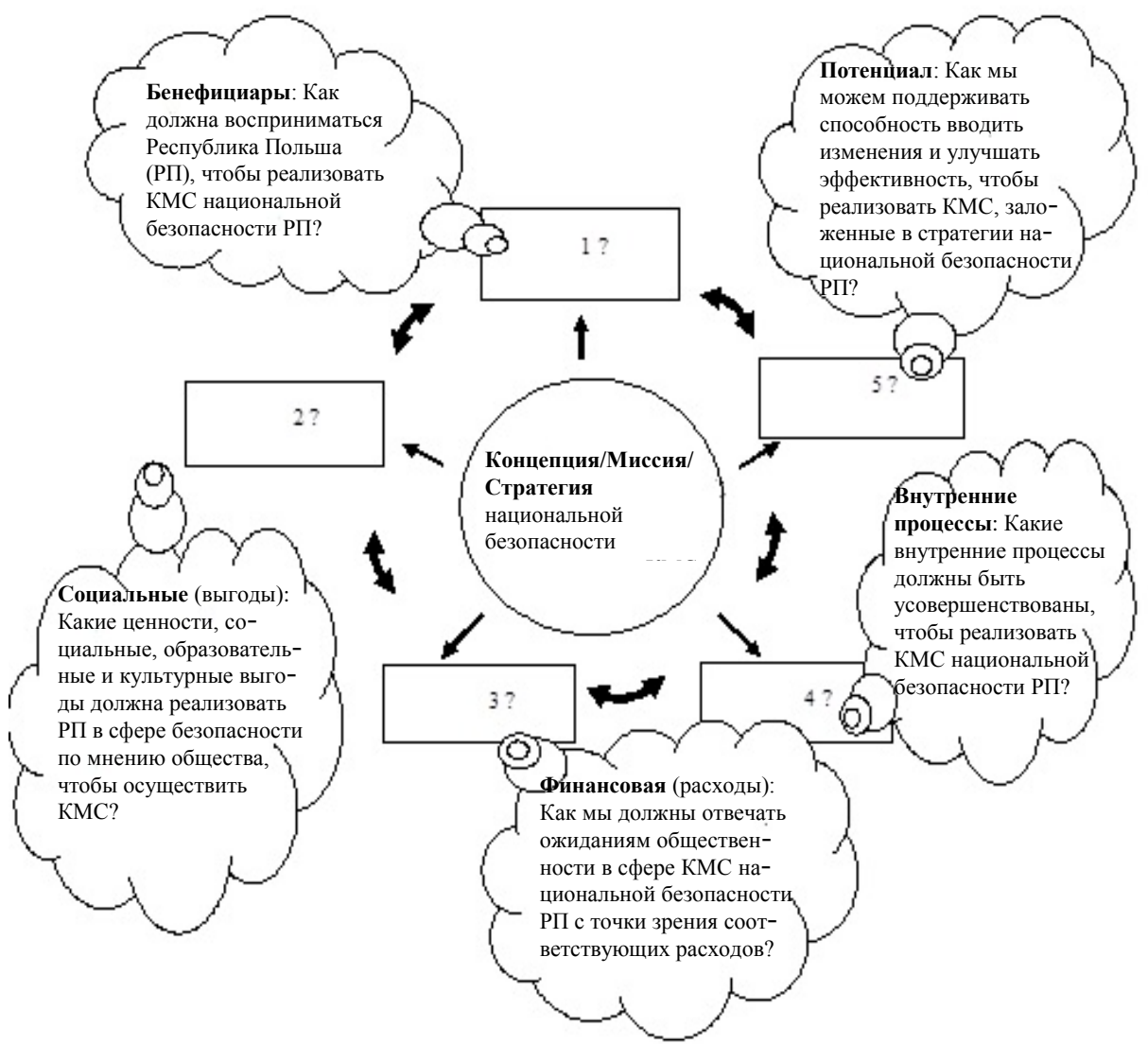

Фигура 7: Точки зрения на Стратегию национальной безопасности в $\mathrm{CCП}^{23}$

22 A. Nowakowska-Krystman, "Strategiczna karta wyników jako narzędzie strategii bezpieczeństwa narodowego," in Strategia bezpieczeństwa narodowego. Czesść II - praca naukowobadawcza, ed. J. Gryz (Warsaw: NDU, 2011), 129. 
3. Финансовые расходы: эта точка зрения учитывает как расходы субъекта, так и социальную цену, связанную с деятельностью субъекта и оплачиваемую обществом; основной целью является уменьшение прямых расходов и социальной цены, необходимых для реализации концепции, миссии и стратегии

4. Внутренние процессы: эта точка зрения определяет, как субъект должен настроить процессы, чтобы наилучшим образом удовлетворять потребностям бенефициаров

5. Потенциал: определяет, как субъект (сотрудники, службы) должны развиваться для того, чтобы реализовать воспринятые концепции, миссии и стратегию национальной безопасности.

Каплан и Нортон считают, что в модифицированной структуре Сбалансированной системы индикаторов для субъекта, участвующего в предоставлении публичных услуг, ключевое значение имеют первые три точки зрения (т.е. бенефициары, социальные выгоды и финансовые расходы). Только после того, как будут установлены соответствующие цели в этих измерениях, можно идентифицировать внутренние процессы и потенциал развития (смотри фиг.8).

Каплан и Нортон подчеркивают факт, что большинство таблиц для таких субъектов раскрывает оперативное совершенство - т.е. они сфокусированы на внутренних процессах, не уделяя достаточного внимания бенефициарам. Однако, в случае долгосрочного жизненного цикла данной услуги, ключевым элементом для успеха является совершенство процессов с учетом потребностей потребителей. ${ }^{24}$ Стоит дополнить, что каждая из упомянутых точек зрения Сбалансированной системы показателей может потребовать от четырех до семи измерителей. Таким образом, количество измерителей будет зависеть от числа точек зрения. ${ }^{25}$

В итоге можно сказать, что идея Сбалансированной системы показателей со временем менялась. Сначала ее использовали в качестве инструмента для мониторинга процесса менеджмента, а потом в качестве инструмента для поддержки реализации стратегии. В настоящее время это инструмент, интегрированный со стратегией, используемый для трансформации долгосрочных целей в текущие цели. Она так же позволяет постоянный контроль, но только если деятельность субъекта, его концепция, миссия и стратегические цели согласованы.

ССП предлагает новую модель измерения результатов и отчета результатов. Сейчас финансовые показатели недостаточны, поскольку наряду с информацией о финансовых результатах прошлой деятельности есть необходимость в информации о деятельности, которая может оказать влияние на будущие финансовые результаты. Сбалансированная система показателей определяет стратегические цели

23 A. Nowakowska-Krystman, "Strategiczna karta wyników jako narzędzie strategii bezpieczeństwa narodowego," 130.

24 Kaplan and Norton, Strategiczna karta wyników, 25.

25 Предприятия должны использовать до 25 стратегических измерителей. See Kaplan and Norton, Strategiczna karta wyników, 151-53. 


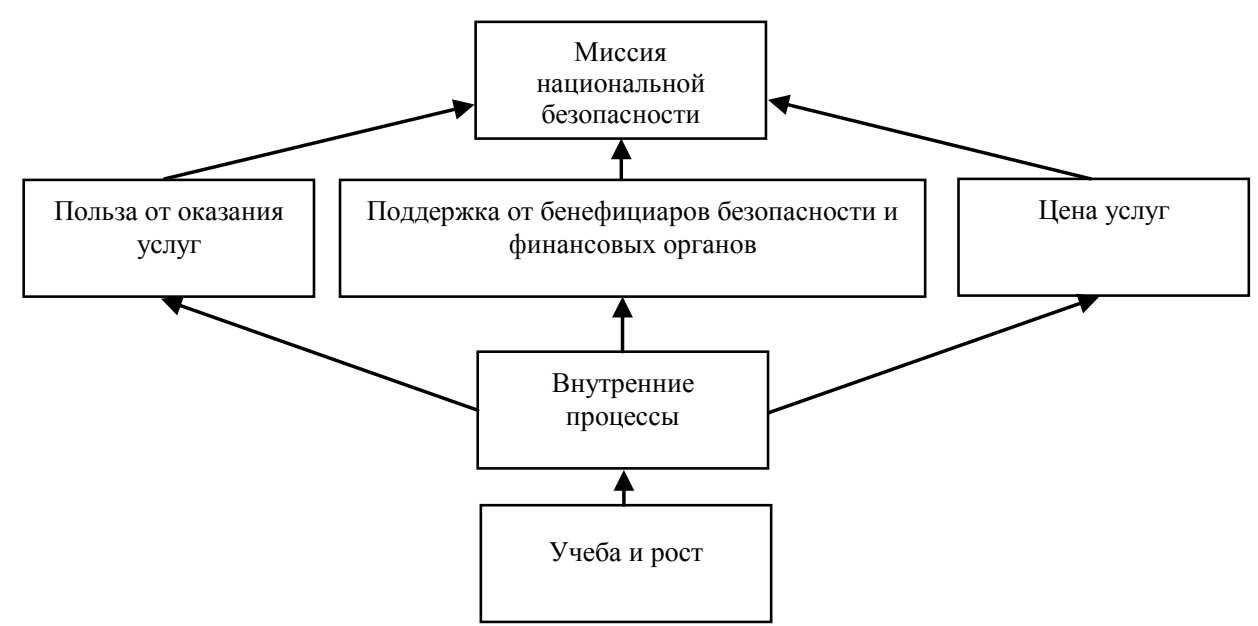

Фигура 8: Модифицированная сбалансированная система показателей для организации, предоставляющей публичные услуги. ${ }^{26}$

организации, которые выходят за рамки финансовых показателей. ${ }^{27}$ Предполагая, что менеджмент не ограничен до менеджмента материальных активов, и измерение его качества (эффективности и прибыльности) основывается не только на финансовых показателях, становится все более важно приобретать и использовать интеллектуальные ресурсы и нефинансовые показатели деятельности на всех уровнях менеджмента. Однако, все измерители должны быть сбалансированы. ${ }^{28}$ Поэтому ССП является попыткой сбалансировать финансовые и нефинансовые показатели. Следовательно, ее можно применять при функционировании организаций, предоставляющих публичные услуги. Более того, она является попыткой сбалансировать долгосрочные и краткосрочные цели, прослеживающие и направляющие индикаторы, внутреннюю и внешнюю эффективность.

Похоже, что Систему сбалансированных показателей можно использовать для облегчения реализации стратегии национальной безопасности. Есть только один вопрос: если определенные точки зрения достаточны для описания целей национальной безопасности, следует ли их дополнять и заменять другими? Если ответ «да», то какие аспекты должны их заменить? Эти и другие вопросы должны стать предметом дискуссий между представителями науки и практики в сфере безопасности.

26 Там же, 131.

27 P. Zob. P. Dżurak, and E.R. Stanoch, "Czy mamy do czynienia z 'rewolucją' systemu pomiaru i oceny działań przedsiębiorstwa?” Controling i Rachunkowość Zarządcza 1 (2001).

28 Kaplan and Norton, Strategiczna karta wyników, 17, 23, 29. 


\section{Контроль стратегических целей национальной безопасности}

Определение стратегических целей является жизненно важным, но если за ним не последует применение и контроль, оно может стать беспредметным. Без контроля предположения - даже если они и являются правильными - не станут реальностью. Сбалансированная система показателей может стать инструментом, который будет полезным при эффективной передаче стратегических предположений исполнителям, что может оказать существенное влияние на сбалансированное развитие страны.

На основе документа, озаглавленного Стратегия национальной безопасности Республики Польша, были идентифицированы восемь областей безопасности (табл. 2, столб 1). В соответствие с методологией ССП нам необходимо идентифицировать стратегические цели (табл. 2, столбы 3,4$)$ и оперативные цели (табл. 2, столб 6) в этих восьми областях, и на этой основе вывести сбалансированные измерители (табл. 2, столб 11). Чтобы измерить публичную задачу в рамках обозначенных аспектов, мы должны учитывать: ${ }^{29}$

1. Гравитацию (вес): В какой степени цели важны в отношении веса потребностей? (смотри табл. 2, столб 5)

2. Эффективность: В какой степени конкретная задача способствует достижению конкретной цели? Больше ли отношение цена/польза, чем единица? Является ли применяемая при реализации задачи система ценностей приемлемой для общества?

3. Функциональность: Оказывает ли данная задача влияние на целевую группу бенефициаров, что касается удовлетворения их потребностей?

4. Устойчивость: В какой степени мы можем ожидать, что от выполнения задачи последуют изменения?

Формула, представленная в форме таблиц 2 и 3, может оказаться полезной при реализации определенных предположений, касающихся структуры Сбалансированной системы показателей при подготовке, применении и контролю реализации стратегии национальной безопасности.

В процессе реализации целей и задач в рамках национальной безопасности необходимо учитывать политические, экономические и военные действия, в которых для этой цели участвуют конкретные акторы - т.е. органы и институции, принадлежащие законодательной, исполнительной и судебной власти, в том числе парламент, президент Республики Польша, Совет министров и центральные органы государственной администрации (смотри табл. 2, столб 10). ${ }^{30}$ Устанавливая рамки ответственности разных государственных органов и институций, важно обращать внимание на правовые нормы, касающиеся конкретных сфер националь-

29 A. Nowakowska-Krystman, "Strategiczna karta wyników," 134.

30 Strategia bezpieczeństwa narodowego Rzeczpospolitej Polskiej (Warsaw, 2007), 21. 
ной безопасности и регулировать задачи и компетенции исполнительных органов. ${ }^{31}$

В соответствие с методологией, разработанной для Сбалансированной системы показателей, реализация стратегии сопровождается постоянным мониторингом соответствия текущей деятельности субъекта с долгосрочными целями национальной безопасности и оценкой эффективности выполнения задач разными акторами. Эта точка зрения должна быть согласована с отношением к контролю менеджмента, что предполагает, что в организациях публичного сектора, как правило, предпринимаются соответствующие действия, обеспечивающие выполнение целей и задач в рамках обязательных норм законодательства наиболее эффективным, экономичным и требующим наименьшей затраты времени способом. ${ }^{32}$

Оценка контроля менеджмента и консультантская деятельность, помогающие данному министру при реализации его/ее целей и задач, осуществляется функцией внутреннего аудита. Анализ несоответствий (соответствие) при реализации стратегии можно осуществлять по отдельности для каждой стратегической области, и даже для каждой стратегической цели, в соответствии с формулой, представленной ниже (смотри табл. 3). Очень важно то, чтобы обнаруженные отличия от принятых величин измерителей, достигнутых в запланированное время (табл. 3, столб 6 , столб 7), были тщательно проанализированы. Для отличий по времени и значению возможно установить допустимые отклонения: если отличие выходит за рамки допустимого отклонения, будут необходимы коррекции стратегических предположений или изменения, касающиеся субъекта, отвечающего за реализацию функций данной стратегической цели (табл. 3, столб 12). Следовательно, необходимо определить критические значения показателей. Если они будут превышены (достигнутое значение ниже), это приведет к необходимости предпринять определенные корректирующие действия по соответствующим каналам (табл. 3 , столб 10, столб 11). Таким образом, контроль может оказывать существенное влияние на процесс принятия решений. ${ }^{33}$

В целом можно сказать, что до того как была разработана таблица взвешенных показателей, возможности контроля соответствия достигнутых результатов принятой стратегии были ограничены. ${ }^{34}$ Несмотря на широту охватываемого спектра, Система сбалансированных показателей не загружает органы, занимающиеся менеджментом, излишней информацией благодаря тому, что выбрано ограниченное количество показателей. Кроме того, очень важно то, что в ССП возможно создавать новые измерители, которые лучше подходят в конкретной ситуации.

Стратегия национальной безопасности является вышестоящей для стратегий исполнительных органов. Полагая, что стратегия национальной безопасности является основополагающим документом, мы должны решать, насколько подробной

31 Смотри Bezpieczeństwo Narodowe Polski w XXI wieku (Warsaw: Bellona, 2006), 171-80.

32 Art. 68 ust. 1 z dnia 27 sierpnia 2009 o finansach publicznych (Dz. U. Nr 157 poz. 1240).

33 A. Nowakowska-Krystman, "Strategiczna karta wyników," 134.

34 See A. Nowakowska-Krystman, "Strategiczna karta wyników." 
Таблица 2: Сбалансированная система показателей для Стратегии национальной безопасности Республики Польша

\begin{tabular}{|c|c|c|c|c|c|c|c|c|c|c|}
\hline 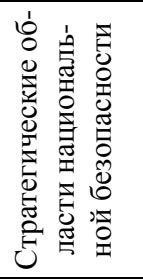 & 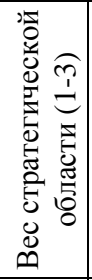 & 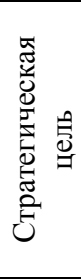 & 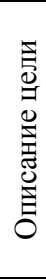 & 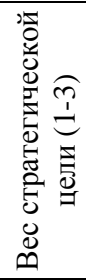 & 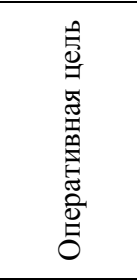 & 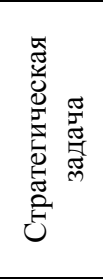 & 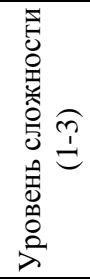 & 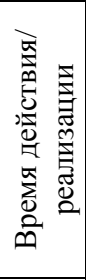 & 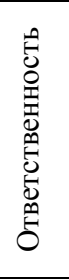 & 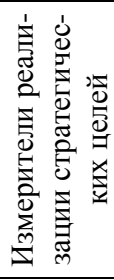 \\
\hline 1. & 2. & 3. & 4. & 5. & 6. & 7. & 8. & 9. & 10. & 11. \\
\hline \multirow{3}{*}{$\begin{array}{l}\text { 1. Внешн } \\
\text { яя без- } \\
\text { опас- } \\
\text { ность }\end{array}$} & \multirow{3}{*}{$\begin{array}{c}\text { вес } \\
1\end{array}$} & g1. & $\ldots$ & ws1 & $\mathrm{g} 1.1, \mathrm{~g} 1.2$ & $\mathrm{t} 1, \mathrm{t} 2, \mathrm{t} 3$ & $\ldots$ & tp1 & M... & w1-w5 \\
\hline & & $\ldots$ & $\ldots$ & $\ldots$ & $\ldots$ & $\ldots$ & $\ldots$ & $\ldots$ & M... & w1-w5 \\
\hline & & gn. & $\ldots$ & wsn & g5.1, g5.2 & $\mathrm{t} 1, \mathrm{t} 2, \mathrm{t} 3$ & $\ldots$ & tp... & M... & w1-w5 \\
\hline \multirow{3}{*}{$\begin{array}{l}\text { 2. Во- } \\
\text { енная } \\
\text { безопас- } \\
\text { ность }\end{array}$} & \multirow{3}{*}{$\begin{array}{c}\text { вес } \\
2\end{array}$} & g1. & $\ldots$ & ws 1 & $\mathrm{~g} 1.1, \mathrm{~g} 1.2$ & $\mathrm{t} 1, \mathrm{t} 2, \mathrm{t} 3$ & $\ldots$ & tp... & M... & w1-w5 \\
\hline & & $\ldots$ & $\ldots$ & $\ldots$ & $\ldots$ & $\ldots$ & $\ldots$ & $\ldots$ & M... & w1-w5 \\
\hline & & gn. & $\ldots$ & wsn & g5.1, g5.2 & $\mathrm{t} 1, \mathrm{t} 2, \mathrm{t} 3$ & $\ldots$ & tp... & M... & w1-w5 \\
\hline \multirow{3}{*}{$\begin{array}{l}\text { 3. Внутре } \\
\text { нняя } \\
\text { безопас- } \\
\text { ность }\end{array}$} & \multirow{3}{*}{$\begin{array}{c}\text { вес } \\
3\end{array}$} & g1. & $\ldots$ & ws1 & $\mathrm{g} 1.1, \mathrm{~g} 1.2$ & $\mathrm{t} 1, \mathrm{t} 2, \mathrm{t} 3$ & $\ldots$ & tp... & M... & w1-w5 \\
\hline & & $\ldots$ & $\ldots$ & $\ldots$ & $\ldots$ & $\ldots$ & $\ldots$ & $\ldots$ & M... & w1-w5 \\
\hline & & gn. & $\cdots$ & wsn & g5.1, c5.2 & $\mathrm{t} 1, \mathrm{t} 2, \mathrm{t} 3$ & $\cdots$ & tp... & M... & w1-w5 \\
\hline \multirow{3}{*}{$\begin{array}{l}\text { 4. Гражда } \\
\text { нская } \\
\text { безопас- } \\
\text { ность }\end{array}$} & \multirow{3}{*}{$\begin{array}{c}\text { вес } \\
4\end{array}$} & g1. & $\ldots$ & ws1 & $\mathrm{g} 1.1, \mathrm{~g} 1.2$ & $\mathrm{t} 1, \mathrm{t} 2, \mathrm{t} 3$ & $\ldots$ & tp... & M... & w1-w5 \\
\hline & & $\ldots$ & $\ldots$ & $\ldots$ & $\ldots$ & $\ldots$ & $\ldots$ & $\ldots$ & M... & w1-w5 \\
\hline & & gn. & $\ldots$ & wsn & g5.1, g5.2 & $\mathrm{t} 1, \mathrm{t} 2, \mathrm{t} 3$ & $\cdots$ & tp... & M... & w1-w5 \\
\hline \multirow{3}{*}{$\begin{array}{l}\text { 5. Со- } \\
\text { циальная } \\
\text { безопас- } \\
\text { ность } \\
\end{array}$} & \multirow{3}{*}{$\begin{array}{c}\text { вес } \\
5\end{array}$} & g1. & $\ldots$ & ws1 & $\mathrm{g} 1.1, \mathrm{~g} 1.2$ & $\mathrm{t} 1, \mathrm{t} 2, \mathrm{t} 3$ & $\ldots$ & tp... & M... & w1-w5 \\
\hline & & $\ldots$ & $\ldots$ & $\ldots$ & $\ldots$ & $\ldots$ & $\ldots$ & $\ldots$ & M... & w1-w5 \\
\hline & & gn. & $\ldots$ & wsn & g5.1, g5.2 & $\mathrm{t} 1, \mathrm{t} 2, \mathrm{t} 3$ & $\ldots$ & tp... & M... & w1-w5 \\
\hline \multirow{3}{*}{$\begin{array}{l}\text { 6. Эко- } \\
\text { номи- } \\
\text { ческая } \\
\text { безопас- } \\
\text { ность }\end{array}$} & \multirow{3}{*}{$\begin{array}{c}\text { вес } \\
6\end{array}$} & g1. & $\ldots$ & ws 1 & $\mathrm{~g} 1.1, \mathrm{~g} 1.2$ & $\mathrm{t} 1, \mathrm{t} 2, \mathrm{t} 3$ & $\ldots$ & tp... & M... & w1-w5 \\
\hline & & $\ldots$ & $\ldots$ & $\ldots$ & $\ldots$ & $\ldots$ & $\ldots$ & $\ldots$ & M... & w1-w5 \\
\hline & & $\mathrm{cn}$. & $\ldots$ & wsn & g5.1, g5.2 & $\mathrm{t} 1, \mathrm{t} 2, \mathrm{t} 3$ & $\cdots$ & tp... & M... & w1-w5 \\
\hline \multirow{3}{*}{$\begin{array}{l}\text { 7. Эко- } \\
\text { логиче- } \\
\text { ская } \\
\text { безопас- } \\
\text { ность }\end{array}$} & \multirow{3}{*}{$\begin{array}{c}\text { вес } \\
7\end{array}$} & g1. & $\ldots$ & ws1 & $\mathrm{g} 1.1, \mathrm{~g} 1.2$ & $\mathrm{t} 1, \mathrm{t} 2, \mathrm{t} 3$ & $\ldots$ & tp... & M... & w1-w5 \\
\hline & & $\ldots$ & $\ldots$ & $\ldots$ & $\ldots$ & $\ldots$ & $\ldots$ & $\ldots$ & M... & w1-w5 \\
\hline & & gn. & $\cdots$ & wsn & g5.1, g5.2 & $\mathrm{t} 1, \mathrm{t} 2, \mathrm{t} 3$ & $\cdots$ & tp... & M... & w1-w5 \\
\hline \multirow{3}{*}{$\begin{array}{l}\text { 8. Инф. и } \\
\text { коммун. } \\
\text { безопас- } \\
\text { ность }\end{array}$} & \multirow{3}{*}{$\begin{array}{c}\text { вес } \\
8\end{array}$} & g1. & $\ldots$ & ws1 & $\mathrm{g} 1.1, \mathrm{~g} 1.2$ & $\mathrm{t} 1, \mathrm{t} 2, \mathrm{t} 3$ & $\ldots$ & tp... & M... & w1-w5 \\
\hline & & $\ldots$ & $\ldots$ & $\ldots$ & $\ldots$ & $\ldots$ & $\ldots$ & $\ldots$ & M... & w1-w5 \\
\hline & & gn. & $\cdots$ & wsn & g5.1, g5.2 & $\mathrm{t} 1, \mathrm{t} 2, \mathrm{t} 3$ & $\ldots$ & tpn & M... & w1-w5 \\
\hline
\end{tabular}




\section{Легенда:}

вес 1-вес 8: вес стратегической области: (1 - существенная, 2 - важная, 3 - жизненно важная)

ws1 ... ws5: вес стратегической цели: (1 - существенная, 2 - важная, 3 - жизненно важная)

Сложность задачи: (1 - легкая, 2 - сложная, 3 - очень сложная)

Измерители стратегической цели c: w1 - точки зрения бенефициаров; w2 -точки зрения социальной пользы; w3 - финансовой точки зрения; w4 - точки зрения внутренних процессов; w5 - точки зрения потенциала

М - Министр

Таблица 3: Контроль результатов Стратегии национальной безопасности в соответствии с принятыми измерителями.

\begin{tabular}{|c|c|c|c|c|c|c|c|c|c|c|c|}
\hline \multirow{2}{*}{ 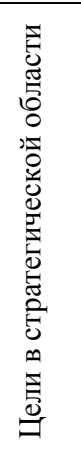 } & \multicolumn{2}{|c|}{ План } & \multicolumn{2}{|c|}{$\begin{array}{c}\text { Выполне- } \\
\text { ние }\end{array}$} & \multicolumn{2}{|c|}{ Несоответствие } & \multicolumn{2}{|c|}{$\begin{array}{c}\text { Допусти- } \\
\text { мые от- } \\
\text { клонения }\end{array}$} & \multicolumn{2}{|c|}{$\begin{array}{l}\text { Критиче- } \\
\text { ское } \\
\text { значение }\end{array}$} & \multirow{2}{*}{ 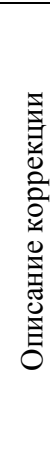 } \\
\hline & 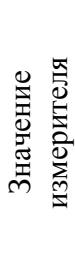 & 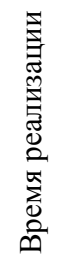 & 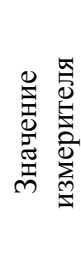 & 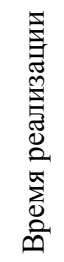 & 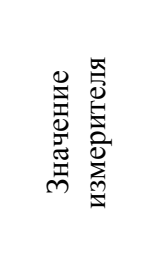 & 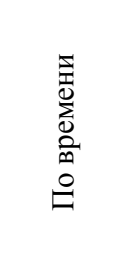 & 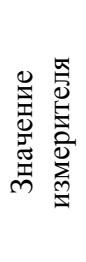 & 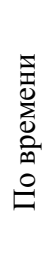 & 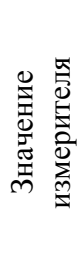 & 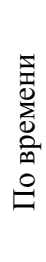 & \\
\hline 1 & 2 & 3 & 4 & 5 & 6 & 7 & 8 & 9 & 10 & 11 & 12 \\
\hline $\mathrm{g} 1$. & wp1 & tp1 & ww1 & tw1 & ww1-wp1 & tw1-tp1 & $\ldots$ & $\ldots$ & $\ldots$ & $\ldots$ & $\ldots$ \\
\hline g2. & wp2 & tp2 & ww2 & tw2 & ww2-wp2 & $\operatorname{tw} 2-\operatorname{tp} 2$ & $\ldots$ & $\ldots$ & $\ldots$ & $\ldots$ & $\ldots$ \\
\hline g3. & wp3 & tp3 & ww3 & tw3 & ww3-wp3 & tw2-tp2 & $\ldots$ & $\ldots$ & $\ldots$ & $\ldots$ & $\ldots$ \\
\hline
\end{tabular}

она должна быть, в частности, того, что касается при адаптировании измерителей, соответствующих стратегическим целям. Это так потому, что должностные лица или органы, ответственные за реализацию конкретных исполнительных стратегий, будут нести ответственность за несоответствия при реализации целей, вычисляемых на основе определенных измерителей.

И последнее, существует проблема: кто должен осуществлять стратегию? Можно полагать, что основная ответственность лежит на публичной администрации, чей анализ может быть выполнен неправительственными организациями. Однако, все еще остается вопрос, кто будет оценивать ее реализацию и на основа- 
нии каких измерителей. Эти вопросы имеют отражение во многих аспектах жизни, и формулирование стратегии национальной безопасности на основании Сбалансированной системы показателей может помочь найти правильные ответы.

\section{Выводы}

С точки зрения сбалансированного развития страны в сфере безопасности подготовка документа, который уравновешивает интересы в разных областях, является очень важной. Такой документ должен давать руководящие положения, которые могут быть трансформированы в конкретные цели и деятельности. Каждая страна, которая разрабатывает стратегию - в том числе и стратегию национальной безопасности, - должна располагать знанием состояния как внутренней, так и внешней среды. Правильно проведенные исследования становятся основанием для правильных стратегических предположений. Применение Сбалансированных показателей в сфере менеджмента национальной безопасности требует адаптирование этого метода к характеру конкретной проблемы. Поэтому можно ожидать, что скоро мы найдем на рынке публикации, представляющие возможности для подготовки и каскадирования Системы сбалансированных показателей, указывающей точки зрения, области, стратегические цели и измерители, и вычисление степени их реализации для использования данным государством.

В заключение в свете знаний, предоставляемых литературой по данному вопросу, похоже, что ССП станет эффективной формой планирования, реализации и контроля стратегии национальной безопасности. Составление сбалансированных таблиц показателей для стратегии национальной безопасности должно начинаться с установления концепции и миссии страны в смысле безопасности. Затем надо провести работу по подготовке стратегии, которая определяет приоритеты, например стратегические факторы для успешного обеспечения безопасности, для того, чтобы быть в состоянии определить стратегические цели в каждой из перечисленных областей. И последнее, измерители достижений выбираются в рамках принятых точек зрения. Это может оказаться серьезным препятствием, поскольку нам необходимо создать такие показатели, которые будут измерять степень реализации концепции национальной безопасности, которая определяется через стратегические цели. Таким образом, конкретный характер субъекта накладывает необходимость разработки уникального набора показателей, используемых в процессе применения ССП с учетом каждой области, в рамках принятых точек зрения. 


\section{Литература}

Bezpieczeństwo Narodowe Polski w XXI wieku. Warsaw: Bellona, 2006.

Chandler, Alfred D.. Strategy and Structure in History of the American Enterprise. Cambridge, MA: Harvard University Press, 1992.

Czuchnowski, J.. Balanced Scorecard. Gdańsk, 2002.

Decenzo, D. A.. Podstawy zarzqdzania. Warsaw: PWE, 2002.

Drążek, Z., and B. Niemczynowicz. Zarzadzanie strategiczne przedsiębiorstwem. Warsaw: PWE, 2003.

Gołębiowski, T.. Zarzqdzanie strategiczne. Planowanie i kontrola. Warsaw: Difin, 2001.

Marchesnay, M.. Zarzqdzanie strategiczne. Geneza i rozwój. Warsaw: Politext, 1994.

Modelski, G.. A Theory of Foreign Policy. London: Praeger, 1962.

Morgentau, H. J.. Decyzje polityczne. Elementy teorii. Warsaw: A. Bodnar, 1985.

Norton, Robert S. Kaplan. Strategiczna karta wyników, Jak przełożyć strategię na działanie. Warsaw: PWN, 2001.

Nowakowska-Krystman, A.. "Strategiczna karta wyników jako narzędzie strategii bezpieczeństwa narodowego." In Strategia bezpieczeństwa narodowego. Część II praca naukowobadawcza, 122. Warsaw: NDU, 2011.

Obłój, K.. Strategia sukcesu firmy. Warsaw: PWE, 2000.

P. Dżurak, Zob. P., and E.R. Stanoch. "Czy mamy do czynienia z 'rewolucją' systemu pomiaru i oceny działań przedsiębiorstwa?" Controling i Rachunkowość Zarzqdcza 1 (2001).

Rajzer, M.. Strategie dywersyfikacji przedsiębiorstw. Warsaw: PWE, 2001.

Rotfeld, Adam D.. Europejski system bezpieczeństwa in statu nascendi. Warsaw: PISM Publishing House, 1990.

Strategia bezpieczeństwa narodowego Rzeczpospolitej Polskiej (National Security Strategy of the Republic of Poland). Warsaw: Ministry of National Defense, 2003.

Tilles, S.. "How to Evaluate Corporate Strategy." Harvard Business Review 41 (1963): 111-121.

Zając, J.. "Bezpieczeństwo - aspekty terminologiczne." In Współczesny wymiar bezpieczeństwa. Między teoriq a praktyka, 18. Warsaw: RWO, 2011. 
Zięba, R.. "Bezpieczeństwo jako cel polityki państwa: aspekty teoretyczne." In Wspótczesny wymiar bezpieczeństwa. Między teoriq a praktyka, 22-24. Warsaw: RWO, 2011. 